\title{
Metabolic Syndrome Associated with Tobacco and Caffeine Products Use Among Refugee Adolescents: Risk of Dyslipidemia
}

\author{
Basma Damiri (1D' \\ Omar Khatib ${ }^{2}$ \\ Zaher Nazzal (iD ${ }^{3}$ \\ Diala Sanduka ${ }^{2}$ \\ Siwar Igbaria ${ }^{2}$ \\ Ammar Thabaleh ${ }^{2}$ \\ Ahmad Farhoud (iD) ${ }^{2}$ \\ Lubna Saudi ${ }^{3}$ \\ Souad Belkebir (iD) ${ }^{3}$ \\ Rayyan Al $\mathrm{Ali}^{4}$ \\ Mohammed Alili \\ Mahmoud Hamdan ${ }^{5}$ \\ Omar A Safarini ${ }^{2}$ \\ Omar Younis ${ }^{2}$ \\ 'Medicine \& Health Science Faculty, \\ Drug, and Toxicology Division, An-Najah \\ National University, Nablus, 00970 , \\ Palestine; ${ }^{2}$ Medicine \& Health Science \\ Faculty, Department of Medicine, An- \\ Najah National University, Nablus, 00970, \\ Palestine; ${ }^{3}$ Medicine \& Health Science \\ Faculty, Family and Community Medicine, \\ An-Najah National University, Nablus, \\ 00970, Palestine; ${ }^{4}$ Medicine \& Health \\ Sciences Faculty, Forensic Medicine \\ Institute, An-Najah National University, \\ Nablus, 00970, Palestine; ${ }^{5}$ Medicine \& \\ Health Science Faculty, Graduate School, \\ Clinical Laboratory Science Program, An- \\ Najah National University, Nablus, 00970, \\ Palestine
}

Correspondence: Basma Damiri Faculty of Medicine and Health Sciences, Drug and Toxicology Division, An-Najah National University, P.O. Box 7, Nablus, 00970, Palestine

Tel +972592234270

Email bdamiri@najah.edu
Introduction: Due to their stressful lives, Palestinian refugees are prone to use cognitive enhancers (CE) and psychostimulant substances (PS). Recognising health problems associated with CE/PS use can indicate how preventive programs should be directed towards adolescents. Unfortunately, research has not thoroughly investigated the health problems related to tobacco and caffeine products, the most socially acceptable CE/PS among Palestinian refugee adolescents.

Methodology: In 2021, schoolchildren from five Palestinian refugee camps ( $=271)$ aged $12-<16$ years agreed to give blood samples and to be interviewed to address the association between metabolic syndrome (MetS) and tobacco smoking, coffee, energy drinks (ED), black tea, and chocolate consumption. MetS was diagnosed based on International Diabetic Federation Criteria. To address the association, we used binary logistic regression models adjusted to age, gender, BMI, and central obesity.

Results: The prevalence of MetS was [17 (6.3\%)]; (7.4\%) in males, $(5.1 \%)$ in females. The prevalence of substance use was as follows: ED [163 (48.9\%)], coffee [255 (76.6\%)], black tea $[295(89.1 \%)]$, cigarette $[35(10.5 \%)]$, waterpipe [59 (17.7\%)], and chocolate [309 $(93.6 \%)]$, with male predominance. Cigarette smokers have increased central obesity ( $p$-value $=0.024$ ), and decreased HDL-cholesterol ( $p$-value=0.015) than non-smokers. Similar results were observed for waterpipe smokers besides the increased levels of triglycerides ( $p$-value $=0.01)$. ED consumers have increased central obesity ( $p$-value $=0.03$ ) and fast blood sugar $(p$-value $=0.003)$ than non-consumers. Chocolate consumers have decreased central obesity ( $p$-value $=0.008$ ) and increased HDL levels ( $p$-value $=0.04$ ) than nonconsumers. ED consumers were significantly at higher risk of MetS (OR=9.97, $\mathrm{p}$-value $=0.019)$ than non-consumers and chocolate consumers were at lower risk of MetS $(\mathrm{OR}=0.14$, $\mathrm{p}$-value $=0.046)$ than non-consumers. Waterpipe smokers were at a higher risk of having increased plasma triglycerides than non-consumers $(\mathrm{OR}=3.4$, $\mathrm{p}$-value $=0.03)$.

Conclusion: The high prevalence of ED consumption and waterpipe smoking in Palestinian refugee adolescents is problematic. Their use was associated with higher odds of MetS, dyslipidemia, and central obesity, which justifies greater attention.

Keywords: refugee adolescents, metabolic syndrome, tobacco smoking, cognitive enhancers and psychostimulants, dyslipidemia, UNRWA

\section{Plain Language Summary}

Metabolic syndrome (MetS) is a clustering of hyperglycemia/insulin resistance, obesity, and dyslipidemia. Although diabetes and obesity have reached an alarming rate among Palestinian refugees, previous research did not investigate the factors behind these serious 
health problems among them. Palestinian refugee children are liable to use cognitive enhancers and psychostimulants (CE/PS) due to their stressful lives. Tobacco and caffeine products are among the most socially acceptable CE/PS among Palestinians. Therefore, they are at higher risk of MetS and ultimately cardiovascular diseases and type 2 diabetes. MetS among CE/ PS users was an under-recognised and neglected health issue in previous national studies. This study showed an alarming prevalence of tobacco smoking and energy drinks (ED) consumption in refugee schoolchildren and those with MetS. The high prevalence of ED consumption and waterpipe smoking among Palestinian refugee schoolchildren is problematic and justifies greater attention. Their use was associated with a higher risk of MetS and dyslipidemia. ED consumers had a significant increase in central obesity and are at higher risk of having MetS than non-consumers. On the other hand, increased plasma triglycerides levels were more prevalent among waterpipe smokers and obese schoolchildren. This problem requires unique treatment and prevention strategies. Our findings suggest the need to integrate CE/PS use prevention and treatment into preexisting health services offered by UNRWA to refugee adolescents in the West Bank to reduce future negative health consequences from their use. Further research investigating the association between ED consumption and other health conditions (in refugees and non-refugees) is recommended.

\section{Introduction}

Adolescent students experience unique challenges making them prone to use psychostimulants (PS) and cognitive enhancers $(\mathrm{CE}) .{ }^{1}$ Psychostimulants are substances that stimulate the central nervous system and are thought to mimic neurotransmitters. ${ }^{2}$ They can elevate mood and are capable of enhancing cognitive performance as well as increasing alertness and arousal. $^{2}$ Nicotine and caffeine are the most legal psychostimulants used worldwide ${ }^{2-4}$ and the most consumed and socially acceptable among Palestinians. ${ }^{5-7}$ Cognitive enhancers are substances that some people use in an attempt to improve the cognitive functions, particularly memory, increase mental alertness and concentration, and boost energy levels and wakefulness. $^{8,9}$ Different studies have demonstrated that nicotine has cognitive-enhancing effects. ${ }^{2,3,10}$ However, caffeine cognition-enhancing properties are still a matter of debate. ${ }^{1-13}$ Although it is ingested predominantly as coffee, many other caffeinecontaining beverages and products exist and contain significant amounts of caffeine, such as tea, chocolate, cocoa beverages, soft drinks, and energy drinks. ${ }^{2,4}$
Previous studies have demonstrated that most Palestinian CE/PS users are adolescents and young adults. $^{6,7,14-18}$ ED consumption and tobacco smoking have become an increasing problem in the West Bank over the last decade. ${ }^{6,17}$ The majority of Palestinian university students had reported daily ED use. ${ }^{16,18}$ Similar results were observed among Palestinian adolescent females, as $41.4 \%$ of adolescent females aged 15 were current ED users. ${ }^{5}$ The initiation age (12 years), the pattern of use (daily), and the co-occurrence of other licit and illicit substance use were the most associated with ED consumption and tobacco smoking. ${ }^{5,6,17}$ Moreover, cigarettes and waterpipe smoking have recently been considered culturally and socially acceptable among Palestinians, especially young women, and refugee children. ${ }^{5,6,17}$ Chronic psychological stress and psychological disorders are common among Palestinian refugees due to their socioeconomic status and lifestyle. ${ }^{6}$ These factors contribute to an increased prevalence of obesity, cardiovascular disease, metabolic syndrome (MetS), and substance abuse. $^{7,19}$

Metabolic syndrome is characterised by a cluster of several metabolic and cardiovascular risk factors such as insulin resistance, abdominal obesity, hypertension, and atherogenic dyslipidemia. ${ }^{20,21}$ MetS has been demonstrated as a common precursor to the development of diabetes mellitus (DM) and cardiovascular diseases. ${ }^{22}$ Although MetS in children remains many years in silence, warning signs can appear during childhood. ${ }^{39}$ Its identification in childhood is likely to reduce the global burden of cardiovascular diseases and type II diabetes in adulthood. $^{23,24}$ Therefore, it is crucial to identify the risk factors of MetS in children.

Tobacco products cause many adverse health effects on smokers and are associated with MetS and metabolic abnormalities. $^{25,26}$ Moreover, different studies have demonstrated that drinks containing a high level of caffeine, like ED and coffee, can affect lipid profile. ${ }^{27-30}$ Although many children and adolescents believe that ED help in losing some weight, heavy consumption can lead to weight gain and an increase in body mass index. ${ }^{31}$ Obesity and MetS and their abnormalities are highly prominent among Palestinians aged 6-68 years, with dyslipidemia being the most common MetS abnormality. ${ }^{19,32-34}$ According to International Diabetes Federation (IDF) definition, the prevalence of MetS in overweight and obese Palestinian schoolchildren was high, and higher in girls $(23.3 \%)$ than boys $(12.3 \%)$ with no significant 
differences. ${ }^{33}$ Moreover, the reduced high-density lipoprotein $(57.2 \%)$ was the most prevalent metabolic abnormality among overweight, and obese schoolchildren, followed by increased fast blood sugar (39.7\%), increased blood pressure $(37.0 \%)$, increased central obesity $(32.2 \%)$, and elevated triglycerides $(24.8 \%){ }^{33}$ However, the risk factors behind these serious health problems among Palestinians were not well established.

Palestinian refugee adolescents are disproportionately likely to use CE/PS for various reasons, including access to substances, coping with traumatic experiences, and social/peer pressure. ${ }^{6,7}$ Given the multiple factors that influence adolescent $\mathrm{CE} / \mathrm{PS}$ use and the increased rate of obesity and MetS among refugees, data on Palestinian refugee's CE/PS use justify greater attention. In addition, recognising health problems associated with $\mathrm{CE} / \mathrm{PS}$ use among adolescents, particularly in conflict and chronicconflict zones, can indicate how preventive programs should be directed towards adolescents. ${ }^{35}$ While the rate of tobacco and caffeine products used to be a growing problem among Palestinian children, research has not thoroughly investigated the complications and the health problems associated with their use among adolescents.

This study aimed to address the risk of MetS and metabolic abnormalities associated with tobacco smoking, energy drinks, coffee, black tea, and chocolate use. This study is a part of ongoing research that aims to investigate the morbidity associated with different psychostimulants and cognitive enhancers use. The results of this study will help better understand MetS among Palestinian society, leading to earlier diagnosis and better outcomes, earlier interventions and treatments regarding tobacco and caffeine products use, and recommendations to direct future research and treatment programs.

\section{Materials and Methods Study Design, Setting, and Tool}

A cross-sectional study was conducted in four refugee camps in the north of the West Bank, Palestine, from February to March 2021. A structured-interview questionnaire was used to address research objectives. The questionnaire used to assess tobacco smoking and caffeine products practice and pattern was used and validated in a previous publication. ${ }^{16} \mathrm{CE} / \mathrm{PS}$ substances tested in this study were cigarettes, waterpipe, ED, coffee, black tea, and chocolate. ED included locally manufactured and imported products available for purchase in Palestine at the time of the study. The current user of a substance is a child who has used substance at least during the past 30 days. ${ }^{36}$ Besides the questionnaire, five $\mathrm{mL}$ of venous blood were collected and were analysed for fasting blood sugar (FBS), high-density lipoprotein (HDL) level, lowdensity lipoprotein (LDL) level, cholesterol, and triglycerides level. All samples were analysed in An-Najah National University Hospital. The diagnostic criteria, anthropometrics, blood pressure measurements, venous blood collection and biochemical analysis, measurement tools accuracy, and precision assessment were used and published in the previous studies. ${ }^{6,19,33}$ Metabolic syndrome was diagnosed according to IDF criteria. According to the new IDF definition, increased abdominal obesity or waist circumference (WC) is required as an essential criterion. ${ }^{37}$ As recommended by IDF criteria, European data for WC was used, as no specific ethnicity cutoff points are available for Palestinian. ${ }^{21,38}$ For children aged between 10 and $<16$ years, a diagnosis of the metabolic syndrome made as to the presence of abdominal obesity (WC $\geq 90$ th percentile or adult cut-off if lower) and the presence of two or more of the other components: Elevated triglycerides $(\geq 1.7 \mathrm{mmol} / \mathrm{L}(\geq 150 \mathrm{mg} / \mathrm{dL}))$, low HDL cholesterol $(<1.03$ $\mathrm{mmol} / \mathrm{L}(<40 \mathrm{mg} / \mathrm{dL})$ ), high blood pressure (Systolic $\geq 130$ $\mathrm{mmHg}$ or diastolic $\geq 85 \mathrm{mmHg}$ ), and elevated blood glucose ( $\geq 5.6 \mathrm{mmol} / \mathrm{L})(\geq 100 \mathrm{mg} / \mathrm{dL})$ or specific treatment for these abnormalities. $^{21,38}$ According to the American College of Cardiology/American and Heart Association Task Force, abnormal total cholesterol and LDL-Cholesterol levels are $\geq 200$ and $\geq 130$, respectively. ${ }^{39}$ The definition of overweight is one standard deviation ( $85 \%$ percentile) body mass index for age and sex, and for obese is two standard deviations (97th percentile) body mass index for age and sex according to World Health Organization (WHO). ${ }^{40}$ Overweight and obese are defined as $85^{\text {th }}$ to less than the $95^{\text {th }}$ percentile and $95^{\text {th }}$ percentile or greater according to Centers for Disease Control and Prevention (CDC). ${ }^{41}$

\section{Study Population and Sampling Technique}

A multi-stage stratified proportional sampling technique was used to select subjects. In the first stage, schoolchildren $\left(7^{\text {th }}-9^{\text {th }}\right.$ grades) from Tulkarm and Nablus refugee camps (5 camps) aged $12-<16$ years (males and females) were recruited. One of the camps was excluded due to the COVID-19 quarantine. The required sample size was 262 (131 males and 131 females). In the first stage, we obtained written informed consent from parents on behalf of the children involved. The schoolchildren were asked to fast for 10-12 hours if they accepted to participate. In the second stage, we interviewed all students in the same class (cluster) who provided signed informed consent 
and agreed to give a blood sample. The participant was included if he/she was a refugee child aged $12-<16$ years, had no psychological conditions, agreed to participate, and his/her parents had signed informed consent for his/her participation. Participants were excluded if they had hypo- or hyperthyroidism, Cushing syndrome, epileptic, or taking regular medications other than anti-diabetic or lipidemic medication as indicated by their parents, if they had haemophilia, psychiatric, cognitive, or developmental disorders, and if they had a fever, flu, or any other acute disease to prevent any possible risk from blood withdrawing. Any child who showed any dissent from participation was excluded from the research.

\section{Ethical Approval and Consent to Participate}

The Ethics Committee of the Institutional Review Board "IRB" at An-Najah National University (ANNU) confirmed the study protocol (IRB Archived number (16) Nov.2019). We obtained parent's informed consent before study conduction. In addition, participation was voluntary, and participants were assured that all data collected would be confidential and available for the researcher only, and coded numbers instead of names were used during analysis and presenting data.

\section{Data Analysis}

All analyses were performed using IBM SPSS Statistics for Mac, version 22 (IBM Corp., Armonk, NY, USA). Kolmogorov-Smirnov test to test the normality of continuous variables distribution was used. We described continuous variables as mean with standard deviation (SD) or medians with (25th, 75th percentiles) and categorical variables as percentages and frequencies. We used binary logistic regression models (Model 1 and Model 2) to evaluate the relative risk by generating the odds ratios (OR) and $95 \%$ confidence intervals (CI) for risk factors. Model 1 was adjusted to age, gender, $\mathrm{BMI}$ and the interaction between gender and BMI was tested. Model 2 was adjusted to age, gender, BMI, FBS, WC, blood cholesterol levels, and the interaction between WC and cholesterol levels were tested.

\section{Results}

The Prevalence, The Pattern of Use, and the Initiation Age of Tested CE/PS Among Refugee Schoolchildren

Schoolchildren $(\mathrm{N}=356)$ aged $12-<16$ years were interviewed, 22 questionnaires were discarded, and 271 (135 males and 136 females) agreed to give blood samples. The mean age was 13.3 years, and the mean weight was $53.8 \mathrm{~kg}$, with no significant difference between genders (p-value $>0.05$ ). The prevalence of substance use was as follows: ED [163 (48.9\%)], coffee [255 (76.6\%)], black tea $[295(89.1 \%)]$, cigarette [35 (10.5\%)], waterpipe [59 $(17.7 \%)]$, and chocolate [309 $(93.6 \%)]$, with male predominance. The percentage of males who smoked daily was $38.5 \%$ for cigarettes and $20.8 \%$ for waterpipes. Males consumed ED daily (26.7\%) or several times (at least 23 times) per week (50.9\%). Chocolate had a daily consumption frequency of $60.8 \%$ (Table 1).

\section{The Prevalence of MetS and Metabolic}

\section{Abnormalities}

The overall prevalence of MetS was $6.3 \%$ (7.4\% in males and $5.1 \%$ in females, $\mathrm{p}$-value $=0.44)$. According to $\mathrm{WHO}$ standards for BMI for children, 22.2\% were overweight, and $24.6 \%$ were obese, with no significant differences between males and females ( $p$-value $=0.69$ ). The overall prevalence of high DBP was $7.9 \%$, and high SBP was $8.8 \%$. The prevalence of other MetS components in descending order was: decreased HDL (40.8\%), increased triglycerides level (10.3\%), increased FBS (8.5\%), increased WC (5.4\%), increased cholesterol level (4.0\%), and increased LDL level (3.7\%). Among these components, only WC differed significantly between males $(9.4 \%)$ and females $(1.2 \%)$ (p-value=0.001) (Table 2).

\section{Differences Metabolic Abnormalities Between Tested CE/PS Users and Non-Users}

Cigarette smokers have a significant increase in WC ( $p$-value $=0.024$ ), and decreased HDL ( $p$-value $=0.015$ ) than non-smokers. Waterpipe smokers have a significant increase in WC ( $p$-value $=0.008$ ), increased level of triglycerides ( $p$-value $=0.01), \quad$ decreased HDL levels ( $p$-value $=0.009)$, and decreased DBP (0.014) than nonsmokers. ED consumers have increased WC ( $p$-value $=0.03$ ) and FBS (p-value $=0.003$ ) than nonconsumer. Chocolate consumers have decreased WC ( $p$-value $=0.008)$ and increased HDL ( $p$-value $=0.04)$ than non-consumers (Table 3).

\section{Univariate Analysis}

Univariate analysis of the association between MetS and different tested CE/PS indicated that an increased risk of 
Table I The Prevalence, Pattern of Use, and Initiation Age of Tested CE/PS in Refugee Schoolchildren

\begin{tabular}{|c|c|c|c|c|c|c|c|c|}
\hline \multirow[t]{2}{*}{ Gender } & \multirow{2}{*}{$\begin{array}{l}\text { Tobacco and } \\
\text { Caffeine } \\
\text { Products }\end{array}$} & \multirow[t]{2}{*}{ Practice ${ }^{\#}$} & \multicolumn{5}{|c|}{ Pattern of Use\# } & \multirow{2}{*}{$\begin{array}{l}\text { Initiation Age in } \\
\text { Years } \\
\text { Median (QI, Q3) } \\
\text { or Mean (SD) }\end{array}$} \\
\hline & & & Daily & $\begin{array}{l}\text { Several } \\
\text { Times } \\
\text { Weekly }\end{array}$ & $\begin{array}{l}\text { Several } \\
\text { Times } \\
\text { Monthly }\end{array}$ & $\begin{array}{l}\text { Several } \\
\text { Times } \\
\text { Yearly }\end{array}$ & Ex-User & \\
\hline Males & $\begin{array}{l}\text { Cigarettes } \\
\text { Waterpipe } \\
\text { Energy drinks } \\
\text { Coffee } \\
\text { Black tea } \\
\text { Chocolate }\end{array}$ & $\begin{array}{l}31(18.2) \\
48(28.2) \\
110(64.7) \\
134(78.4) \\
162(94.7) \\
161(95.3)\end{array}$ & $\begin{array}{l}I 5(38.5) \\
I I(20.8) \\
31(26.7) \\
5 I(40.2) \\
98(64.5) \\
90(60.8)\end{array}$ & $\begin{array}{l}8(20.5) \\
20(37.7) \\
59(50.9) \\
52(40.9) \\
51(33.6) \\
46(31.1)\end{array}$ & $\begin{array}{l}5(\mid 2.8) \\
14(26.4) \\
18(\mid 5.5) \\
15(\mid I .8) \\
I(0.7) \\
I I(7.4)\end{array}$ & $\begin{array}{l}3(7.7) \\
7(13.2) \\
4(3.4) \\
9(7.1) \\
2(1.3) \\
1(0.7)\end{array}$ & $\begin{array}{l}8(20.5) \\
I(1.9) \\
4(3.4) \\
0(0.0) \\
0(0.0) \\
0(0.0)\end{array}$ & $\begin{array}{l}10.2(1.8) \\
11.6(1.4) \\
10.5(2.4) \\
10(7.5,11) \\
9(7,9) \\
6(6,7)\end{array}$ \\
\hline Females & $\begin{array}{l}\text { Cigarettes } \\
\text { Waterpipe } \\
\text { Energy drinks } \\
\text { Coffee } \\
\text { Black tea } \\
\text { Chocolate }\end{array}$ & $\begin{array}{l}4(2.5) \\
11(6.9) \\
53(32.5) \\
121(74.7) \\
133(83.1) \\
148(91.9)\end{array}$ & $\begin{array}{l}0(0.0) \\
3(12.5) \\
16(22.5) \\
25(22.3) \\
71(58.2) \\
70(51.1)\end{array}$ & $\begin{array}{l}I(16.7) \\
4(16.7) \\
29(40.8) \\
55(49.1) \\
36(29.5) \\
47(34.3)\end{array}$ & $\begin{array}{l}I(16.7) \\
4(16.7) \\
7(9.9) \\
24(2 I .4) \\
6(4.9) \\
I I(7.4)\end{array}$ & $\begin{array}{l}3(50.0) \\
8(33.3) \\
14(19.7) \\
8(7.2) \\
9(7.4) \\
3(1.2)\end{array}$ & $\begin{array}{l}I(16.7) \\
5(20.8) \\
5(7.0) \\
0(0.0) \\
0(0.0) \\
6(4.4)\end{array}$ & $\begin{array}{l}11(9.5,11.5) \\
12(11,13) \\
10.4(2.2) \\
11(10,12) \\
9(7,10) \\
6(6,7)\end{array}$ \\
\hline
\end{tabular}

Note: "Data shown as $\mathrm{n}(\%)$.

Abbreviation: CE/PS, cognitive enhancers/psychostimulants.

MetS was significantly associated with cigarette smoking $(\mathrm{OR}=4.60$, p-value $=0.008)$, waterpipe smoking $(\mathrm{OR}=3.29$, $\mathrm{p}$-value $=0.027)$ and $\mathrm{ED}$ consumption $(\mathrm{OR}=5.97$, $\mathrm{p}$-value $=0.002$ ), while chocolate consumption was significantly associated with decreased risk of MetS $(\mathrm{OR}=0.2$, p-value $=0.02$ ) (Table 4).

\section{Model I: Adjusted Binary Logistic Regression Analysis}

Adjusted binary logistic regression analysis for the association between MetS and tested CE/PS indicated that ED consumers were at a higher risk of MetS than nonconsumers $(\mathrm{OR}=9.97, \mathrm{p}$-value $=0.019)$. Chocolate consumers were at a lower risk of MetS than non-consumers $(\mathrm{OR}=0.14$, $\mathrm{p}$-value $=0.046)$. Increased BMI was also associated with increased risk of MetS $(\mathrm{OR}=1.35$, p-value $<0.001$ ) (Table 5). No significant interaction results between BMI and gender were observed. (p-value $>0.05$ ).

\section{Model 2: Adjusted Binary Logistic Regression Analysis}

Adjusted binary logistic regression analysis for the association between increased plasma triglycerides levels and tested CE/PS indicated that waterpipe smokers were at a higher risk of having increased plasma triglycerides than non-smokers $(\mathrm{OR}=3.45, \mathrm{p}$-value $=0.03)$. Increased total cholesterol levels $(\mathrm{OR}=8.99$, $\mathrm{p}$-value $=0.007)$ and $\mathrm{WC}(\mathrm{OR}=4.77$, $\mathrm{p}$-value $=0.02)$ were also significantly associated with an increased risk of high plasma triglycerides levels. No significant interaction results between waist circumferences and cholesterol and glucose were observed (p-value $>0.05$ ) (Table 6).

\section{Discussion}

This study aimed to investigate the risk associated with tobacco and caffeine products use and MetS among Palestinian refugee schoolchildren. There are several remarkable findings in this study. First, refugee males were significantly more likely to be identified as at higher risk of tobacco and caffeine products use than females. Cigarette smoking had a total prevalence of $10.5 \%$, where males $(18.2 \%)$ had a significantly higher prevalence than females $(2.5 \%)$ among refugee schoolchildren. Waterpipe was more common than cigarettes, with a total prevalence of $17.7 \%$ (28.2\% in males and $6.9 \%$ in females). These results (male predominance) were consistent with other local and global countries. ${ }^{6,15-18}$ Second, ED consumption was common among schoolchildren, where its overall prevalence was $48.9 \%$, with a significant male predominance $(64.7 \%)$ compared to females $(32.5 \%)$. This widespread prevalence and gender-based difference are 
Table 2 The Prevalence of MetS and Metabolic Abnormalities in Refugee Schoolchildren

\begin{tabular}{|c|c|c|c|c|c|}
\hline & & Total & Males & Females & P-value \\
\hline MetS & Yes & $17(6.3)$ & $10(7.4)$ & $7(5.1)$ & 0.44 \\
\hline WC $(\mathrm{cm})$ & High & $18(5.4)$ & 16(9.4) & $2(1.2)$ & $0.00 I^{*}$ \\
\hline FBS (mg/dL) & High & $23(8.5)$ & $14(10.4)$ & $9(6.6)$ & 0.26 \\
\hline HDL (mg/dL) & Low & $160(40.8)$ & $78(42.4)$ & $82(39.4)$ & 0.55 \\
\hline Triglycerides (mg/dL) & High & $28(10.3)$ & $16(11.9)$ & $12(8.8)$ & 0.40 \\
\hline Total cholesterol (mg/dL) & High & $I I(4.0)$ & $5(3.7)$ & $6(4.4)$ & 0.78 \\
\hline LDL (mg/dL) & High & $10(3.7)$ & $4(3.0)$ & $6(4.4)$ & 0.75 \\
\hline $\mathrm{DBP}(\mathrm{mmHg})$ & High & $26(7.9)$ & $\mathrm{II}(6.5)$ & $15(9.3)$ & 0.35 \\
\hline $\mathrm{SBP}(\mathrm{mmHg})$ & High & $29(8.8)$ & $\mathrm{II}(6.5)$ & $\mid 8(|| .2)$ & 0.14 \\
\hline \multirow[t]{4}{*}{ BMI based on WHO $\left(\mathrm{kg} / \mathrm{m}^{2}\right)$} & Underweight & |4(4.2) & $9(5.3)$ & $5(3.1)$ & \multirow[t]{4}{*}{0.69} \\
\hline & Normal weight & $164(49.1)$ & $80(46.8)$ & $84(51.5)$ & \\
\hline & Overweight & $74(22.2)$ & $39(22.8)$ & $35(21.5)$ & \\
\hline & Obese & $82(24.6)$ & $43(25.1)$ & $39(23.9)$ & \\
\hline \multirow[t]{4}{*}{ BMI based on CDC $\left(\mathrm{kg} / \mathrm{m}^{2}\right)$} & Underweight & $18(5.4)$ & $13(7.6)$ & $5(3.1)$ & \multirow[t]{4}{*}{0.13} \\
\hline & Normal weight & $182(54.5)$ & $87(50.9)$ & $95(58.3)$ & \\
\hline & Overweight & $67(20.1)$ & $32(18.7)$ & $35(21.5)$ & \\
\hline & Obese & $66(20.1)$ & $39(22.8)$ & $28(17.2)$ & \\
\hline
\end{tabular}

Notes: Data shown as $\mathrm{n}(\%)$; $*$ Significant. Increased WC: $\geq 90$ th percentile, elevated triglycerides: $\geq 150 \mathrm{mg} / \mathrm{dL}, \mathrm{low} \mathrm{HDL}:<40 \mathrm{mg} / \mathrm{dL}, \mathrm{SBP} \geq 130 \mathrm{mmHg}$ or $\mathrm{DBP} 85 \mathrm{mmHg}$, and elevated FBS $\geq 100 \mathrm{mg} / \mathrm{dL}$ ( $\mathrm{l}, 2$;) Cholesterol: $\geq 200 \mathrm{mg} / \mathrm{dL}$; LDL: $\geq 200 \mathrm{mg} / \mathrm{dL}$.

Abbreviations: WC, waist circumference; BMI, body mass index; FBS, fasting blood sugar; HDL, high-density lipoprotein; LDL, low-density lipoprotein; SBP, systolic blood pressure; DBP, diastolic blood pressure; kg, kilogram; m, meter; cm, centimetre; mmHg, millimetre mercury; mg, milligram; dL, deciliter; MetS, metabolic syndrome; CDC, Centers for Disease Control and Prevention; WHO, World Health Organization.

consistent with previous studies involving Palestinian refugee children and children in other countries. ${ }^{6,27,28,42}$ However, this high prevalence and the pattern of ED consumption in children are problematic. A previous study involving Palestinian schoolchildren found a very high prevalence $(95.7 \%)$ of ED consumption among those who use illicit drugs, suggesting an association between the two practices. ${ }^{6}$ Moreover, most ED consumers, either males $(78 \%)$ or females $(63 \%)$, were consuming ED daily or several times weekly, possibly increasing the risk of getting caffeine toxicity, thus potentiating its side effects. $^{43-47}$

Our results showed that $22.2 \%$ of refugee schoolchildren were overweight, and $24.6 \%$ were obese, indicating that refugee adolescents are more likely to develop diseases associated with obesity, such as metabolic diseases and heart diseases. ${ }^{48}$ The overall prevalence of MetS in refugee schoolchildren based on IDF criteria was high $(6.3 \%)$ and significantly higher among obese $(21.5 \%)$ than overweight $(5.2 \%)$ with no gender differences. The absence of previous local research on MetS was one of the most salient constraints in predicting a change in the prevalence of MetS and its components in refugee schoolchildren. A previous local study on MetS among overweight and obese schoolchildren demonstrated that the prevalence of MetS in this group was high $(15.8 \%)$ and was higher in obese $(21.2 \%)$ than overweight $(2.1 \%)$ and schoolchildren with increased central obesity had shown a significant increase in the clustering of metabolic abnormalities. ${ }^{33}$ In this study, the most prevalent metabolic abnormalities between refugee schoolchildren were decreased HDL (40\%), followed by increased triglycerides $(10.3 \%)$ and increased FBS (8.5\%). Moreover, schoolchildren with increased central obesity were at higher risk of having high triglyceride levels. Studies concerning central obesity among Palestinian children are scarce. ${ }^{33,49}$ Central obesity is more indicative of the MetS profile than BMI and independently associated with the other MetS components. ${ }^{50}$ In this study, central obesity was significantly higher in ED users than non-users and cigarette and waterpipe smokers than non-smokers.

Energy drinks are highly caffeinated, sweetened, carbonated beverages, contain $80-300 \mathrm{mg}$ of caffeine and various other stimulants and substances such as guarana, taurine, or vitamins. ${ }^{51,52}$ Exposure to excesses of simple sugars can lead to obesity and insulin resistance ${ }^{51,53}$ which are considered the most significant factors for MetS. ${ }^{37}$ Our results indicated that $\mathrm{ED}$ users have a higher increase in 
Table 3 Differences in Metabolic Abnormalities Between Users (Yes) and Non-Users (No)

\begin{tabular}{|c|c|c|c|c|c|c|}
\hline & \multicolumn{3}{|l|}{ Cigarettes } & \multicolumn{3}{|l|}{ Waterpipe } \\
\hline & Yes & No & P-value & Yes & No & P-value \\
\hline$W C(\mathrm{~cm})$ & $78.9(\mid 5.0)$ & 74.4(II.4) & $0.024 *$ & $78.3(13.7)$ & 74.I(II.3) & $0.008^{*}$ \\
\hline BMI $\left(\mathrm{kg} / \mathrm{m}^{2}\right)$ & $22.8(6.3)$ & $21.9(5.0)$ & 0.15 & $22.8(5.5)$ & $21.8(5.0)$ & 0.055 \\
\hline FBS (mg/dL) & $92.7(6.8)$ & $91.4(7.3)$ & 0.45 & $92.3(7.3)$ & $91.4(7.3)$ & 0.52 \\
\hline Triglycerides (mg/dL) & $99.2(51.2)$ & $94.0(45.1)$ & 0.58 & II5.0(66.7) & $90.7(39.7)$ & $0.01 *$ \\
\hline $\mathrm{HDL}(\mathrm{mg} / \mathrm{dL})$ & $43.4(9.8)$ & $49.4(12.4)$ & $0.015^{*}$ & $45.0(12.5)$ & $49.5(12.1)$ & $0.009 *$ \\
\hline Cholesterol (mg/dL) & $145.9(26.8)$ & | $48.0(27.9)$ & 0.69 & $|48|.(29.5)$ & | 47.8(27.4) & 0.93 \\
\hline LDL (mg/dL) & $85.9(21.1)$ & $88.0(24.6)$ & 0.56 & $89.4(26.0)$ & $87.9(23.9)$ & 0.97 \\
\hline $\mathrm{SBP}(\mathrm{mmHg})$ & $105.8(12.0)$ & $108.5(\mid 4.8)$ & 0.33 & $106.6(13.0)$ & $108.6(14.8)$ & 0.35 \\
\hline \multirow[t]{2}{*}{$\mathrm{DBP}(\mathrm{mmHg})$} & $61.2(12.2)$ & $66.1(13.0)$ & 0.136 & $61.8(10.7)$ & $66.4(13.3)$ & $0.014 *$ \\
\hline & \multicolumn{3}{|l|}{ Coffee } & \multicolumn{3}{|l|}{ Black tea } \\
\hline WC (cm) & $74.9(12.1)$ & $74.9(I I .1)$ & 0.97 & $74.8(12.0)$ & $74.6(10.7)$ & 0.70 \\
\hline BMI $\left(\mathrm{kg} / \mathrm{m}^{2}\right)$ & $21.9(5.1)$ & $22.2(5.2)$ & 0.82 & $21.7(4.8)$ & $23.9(6.5)$ & 0.123 \\
\hline $\mathrm{FBS}(\mathrm{mg} / \mathrm{dL})$ & $91.3(7.2)$ & $92.2(7.3)$ & 0.37 & $91.7(7.4)$ & $90.1(6.3)$ & 0.32 \\
\hline Triglycerides (mg/dL) & $94.0(42.5)$ & $95.9(53.6)$ & 0.87 & $93.0(47.2)$ & $91.7(31.3)$ & 0.63 \\
\hline $\mathrm{HDL}(\mathrm{mg} / \mathrm{dL})$ & $48.4(12.2)$ & $50.1(12.5)$ & 0.32 & $48.8(12.4)$ & $49.7(10.9)$ & 0.58 \\
\hline Cholesterol (mg/dL) & 147.6(26.6) & | 48.4(30.7) & $0.7 \mathrm{I}$ & 147.2(26.9) & $154.5(33.8)$ & 0.38 \\
\hline LDL (mg/dL) & $88.3(23.0)$ & $87.7(27.4)$ & 0.55 & $87.5(23.2)$ & $93.7(31.2)$ & 0.36 \\
\hline $\mathrm{SBP}(\mathrm{mmHg})$ & $107.9(14.0)$ & $109.1(16.0)$ & 0.54 & $107.9(14.3)$ & $110.0(15.7)$ & 0.41 \\
\hline \multirow[t]{2}{*}{$\mathrm{DBP}(\mathrm{mmHg})$} & $65.6(12.4)$ & $65.6(14.8)$ & 0.92 & $65.2(12.7)$ & $68.0(15.2)$ & 0.24 \\
\hline & \multicolumn{3}{|c|}{ Energy drinks } & \multicolumn{3}{|l|}{ Chocolate } \\
\hline $\mathrm{WC}(\mathrm{cm})^{\mathrm{a}}$ & $77.1(13.2)$ & $72.8(10.1)$ & $0.03^{*}$ & $74.4(I I .8)$ & $81.4(116.6)$ & $0.008^{*}$ \\
\hline BMI $\left(\mathrm{kg} / \mathrm{m}^{2}\right)$ & $22.5(5.5)$ & $21.5(4.8)$ & 0.17 & $21.8(5.0)$ & $24.2(5.8)$ & 0.13 \\
\hline FBS (mg/dL) & $93.0(7.0)$ & $90.2(7.3)$ & $0.003^{*}$ & $91.6(7.4)$ & $91.1(6.4)$ & 0.98 \\
\hline Triglycerides (mg/dL) & $99.1(48.6)$ & $90.5(42.7)$ & 0.26 & $94.6(46.6)$ & $94.7(33.8)$ & 0.59 \\
\hline $\mathrm{HDL}(\mathrm{mg} / \mathrm{dL})$ & $48.9(12.9)$ & $48.8(11.7)$ & 0.91 & $49.2(12.5)$ & $43.6(8.4)$ & $0.04 *$ \\
\hline Cholesterol (mg/dL) & 149.3(28.0) & | 46.5(27.6) & 0.55 & I 48.I(28.0) & I $44.4(24.5)$ & 0.51 \\
\hline LDL (mg/dL) & $89.4(24.5)$ & $87.1(24.0)$ & 0.27 & $87.9(24.5)$ & $90.6(21.4)$ & 0.79 \\
\hline $\mathrm{SBP}(\mathrm{mmHg})$ & $108.3(14.3)$ & $108.1(14.8)$ & 0.95 & $108.2(14.4)$ & $108.5(17.6)$ & 0.54 \\
\hline $\mathrm{DBP}(\mathrm{mmHg})$ & $65.1(13.9)$ & $66.0(12.1)$ & 0.53 & $65.8(12.9)$ & $63.0(14.6)$ & 0.92 \\
\hline
\end{tabular}

Notes: Data shown in mean (SD); *Significant. Increased WC: $\geq 90$ th percentile, Increased FBS: $\geq 100 \mathrm{mg} / \mathrm{dL}$; increased triglycerides: $\geq 150 \mathrm{mg} / \mathrm{dL}$, Low HDL: $<40 \mathrm{mg} / \mathrm{dL}$, Increased SBP: $\geq 130 \mathrm{mmHg}$ or DBP $\geq 85 \mathrm{mmHg}$; Increased Cholesterol: $\geq 200 \mathrm{mg} / \mathrm{dLl}$; Increased LDL: $\geq 200 \mathrm{mg} / \mathrm{dL}$.

Abbreviations: WC, waist circumferences; BMI, body mass index; FBS, fasting blood sugar; HDL, high density lipoprotein; LDL, low density lipoprotein; SBP, systolic blood pressure; DBP, diastolic blood pressure; $\mathrm{kg}$, kilogram; $\mathrm{m}$, meter; $\mathrm{cm}$, centimetre; $\mathrm{mmHg}$, millimetre mercury; $\mathrm{mg}$, milligram; dL, deciliter.

central obesity and fast blood sugar than non-users. In agreement with previous studies, the adjusted binary logistic regression results revealed that $\mathrm{ED}$ users had a 5 -folds higher risk of having MetS than non-users. ${ }^{54,55}$ This association probably results from high sugar and caffeine levels in these drinks, which affect glucose profile. ${ }^{55}$ Our results indicated that ED consumption was not associated with high levels of triglycerides. A previous study demonstrated that ED consumption was associated with increased triglycerides at age 20 and a low level at age 22 years. ${ }^{56}$ Collectively, these results suggest that there is no clear evidence for the association between ED consumption and high triglycerides in adolescents. Overall, there seems to be a high level of under-recognised and undertreated MetS among refugee schoolchildren, specifically ED consumers. Considering the high prevalence and the pattern of ED consumption among refugee schoolchildren and its association with MetS and other side effects, we recommend implying substantial restrictions on Palestinian children's access to ED in refugee camps and possibly other Palestinian regions. Moreover, we recommend integrating ED consumption screening and cessation strategies into health services provided for Palestinian refugees. In addition, further research is warranted to investigate the 
Table 4 Univariate Analysis for Metabolic Syndrome and Tested CE/PS

\begin{tabular}{|c|c|c|c|c|c|c|}
\hline & & $\begin{array}{l}\text { Have Metabolic } \\
\text { Syndrome }\end{array}$ & $\begin{array}{l}\text { Do Not Have Metabolic } \\
\text { Syndrome }\end{array}$ & $\begin{array}{l}\text { Odds } \\
\text { Ratio }\end{array}$ & $\begin{array}{l}\text { 95\% Confidence } \\
\text { Interval }\end{array}$ & P-value \\
\hline Cigarette smoking & $\begin{array}{l}\text { Yes } \\
\text { No }\end{array}$ & $\begin{array}{l}5(19.2) \\
12(4.9)\end{array}$ & $\begin{array}{l}21(80.8) \\
232(95.1)\end{array}$ & 4.60 & I.48-14.32 & $0.008^{*}$ \\
\hline Waterpipe smoking & $\begin{array}{l}\text { Yes } \\
\text { No }\end{array}$ & $\begin{array}{l}6(14.3) \\
11(4.8)\end{array}$ & $\begin{array}{l}36(85.7) \\
217(95.2)\end{array}$ & 3.29 & I.14-9.45 & $0.027^{*}$ \\
\hline $\begin{array}{l}\text { Energy drink } \\
\text { consumption }\end{array}$ & $\begin{array}{l}\text { Yes } \\
\text { No }\end{array}$ & $\begin{array}{l}14(1 \mid .2) \\
3(2.1)\end{array}$ & $\begin{array}{l}\text { I I I(88.8) } \\
\text { I42(97.9) }\end{array}$ & 5.97 & $1.67-21.29$ & $0.002^{*}$ \\
\hline $\begin{array}{l}\text { Coffee } \\
\text { consumption }\end{array}$ & $\begin{array}{l}\text { Yes } \\
\text { No }\end{array}$ & $\begin{array}{l}13(6.5) \\
4(5.6)\end{array}$ & $\begin{array}{l}187(93.5) \\
67(94.4)\end{array}$ & 1.16 & $0.37-3.70$ & 1.00 \\
\hline $\begin{array}{l}\text { Black tea } \\
\text { consumption }\end{array}$ & $\begin{array}{l}\text { Yes } \\
\text { No }\end{array}$ & $\begin{array}{l}14(5.9) \\
2(6.7)\end{array}$ & $\begin{array}{l}225(94.1) \\
28(93.3)\end{array}$ & 0.87 & $0.19-4.03$ & 0.70 \\
\hline $\begin{array}{l}\text { Chocolate } \\
\text { consumption }\end{array}$ & $\begin{array}{l}\text { Yes } \\
\text { No }\end{array}$ & $\begin{array}{l}13(5.2) \\
4(21.1)\end{array}$ & $\begin{array}{l}236(94.8) \\
15(78.9)\end{array}$ & 0.20 & $0.06-0.71$ & $0.02 *$ \\
\hline Gender & $\begin{array}{l}\text { Male } \\
\text { Female }\end{array}$ & $\begin{array}{l}10(7.4) \\
7(5.1)\end{array}$ & $\begin{array}{l}125(92.6) \\
129(94.9)\end{array}$ & 1.47 & $0.54-3.99$ & 0.45 \\
\hline Body mass index & $\begin{array}{l}\text { Underweight } \\
\text { Normal } \\
\text { weight } \\
\text { Overweight } \\
\text { Obese }\end{array}$ & $\begin{array}{l}0(0.0) \\
0(0.0) \\
3(5.2) \\
14(2 \mid .5)\end{array}$ & $\begin{array}{l}14(100.0) \\
134(100.0) \\
55(94.8) \\
51(78.5)\end{array}$ & & & $<0.001 *$ \\
\hline $\begin{array}{l}\text { Low-Density } \\
\text { Lipoprotein }\end{array}$ & $\begin{array}{l}\text { High } \\
\text { Normal }\end{array}$ & $\begin{array}{l}I(10.0) \\
16(6.1)\end{array}$ & $\begin{array}{l}9(90.0) \\
245(93.9)\end{array}$ & 1.70 & $0.20-14.27$ & 0.62 \\
\hline
\end{tabular}

Notes: Data shown as $\mathrm{n}(\%)$; ${ }^{\text {Significant. }}$

association between ED consumption and MetS and other health conditions in non-refugee children since such results might help better understanding the aetiology of MetS in an early stage of life.
Cardiovascular disease is the most common leading cause of mortality among Palestinians. ${ }^{57}$ A low level of serum HDL cholesterol was established to be an independent risk factor for coronary artery disease and

Table 5 Model I: Adjusted Binary Logistic Regression for MetS and Tested CE/PS Use

\begin{tabular}{|l|l|l|l|l|l|}
\hline Metabolic Syndrome (Yes) ${ }^{\#}$ & Variable & Reference Category & Odds Ratio & 95\% (CI) & P-value \\
\hline Cigarettes smoking & Yes & No & 3.07 & $0.56-16.9$ & 0.20 \\
Waterpipe smoking & Yes & No & 1.36 & $0.30-6.13$ & 0.69 \\
Energy drink consumption & Yes & No & 9.97 & $1.45-68.39$ & $0.019^{*}$ \\
Coffee consumption & Yes & No & 1.22 & $0.27-5.56$ \\
Chocolate consumption & Yes & No & 0.14 & $0.02-0.96$ & 0.80 \\
Black tea consumption & Yes & No & 7.87 & $0.57-109.1$ & 0.12 \\
\hline Gender & Male & Female & 0.79 & $0.16-3.84$ & 0.77 \\
Age & & & 0.80 & $0.40-1.59$ & 0.52 \\
Body Mass Index & & & 1.35 & $1.19-1.52$ & $<0.001 *$ \\
\hline
\end{tabular}

Notes: ${ }^{\#}$ Reference category is No metabolic syndrome; *Significant.

Abbreviations: $\mathrm{Cl}$, confidence interval; MetS, metabolic syndrome; CE/PS, cognitive enhancers/psychostimulants. 
Table 6 Model 2: Adjusted Binary Logistic Regression for Increased Triglycerides and CE/PS Use

\begin{tabular}{|l|l|l|l|l|l|}
\hline \multicolumn{1}{|l|}{ High Triglycerides Plasma Level Yes" } \\
\hline & Variable & Reference & OR & 95\% (CI) \\
\hline Cigarettes smoking & Yes & No & 0.67 & $0.15-3.10$ & P-value \\
Waterpipe smoking & Yes & No & 3.45 & $1.30-10.60$ & 0.611 \\
Energy drinks consumption & Yes & No & 0.94 & $0.33-2.65$ & $0.03^{*}$ \\
Coffee consumption & Yes & No & 0.43 & $0.15-1.20$ & 0.90 \\
Chocolate & Yes & No & 0.59 & $0.13-2.71$ & 0.11 \\
Black tea consumption & Yes & No & 2.00 & $0.33-12.90$ & 0.49 \\
WC & High & Normal & 4.77 & $1.29-17.68$ & 0.45 \\
FBS & High & Normal & 0.99 & $0.93-1.06$ & $0.02^{*}$ \\
Cholesterol & High & Normal & 8.99 & $1.85-43.75$ & 0.835 \\
\hline Gender & Male & Female & 1.35 & $0.47-3.85$ & $0.007^{*}$ \\
Age & & & 0.78 & $0.47-1.29$ & 0.57 \\
Body mass index (BMI) & & & 1.05 & $0.95-1.17$ \\
\hline
\end{tabular}

Notes: "Reference category is Normal triglycerides plasma level; *Significant. Increased WC: $\geq 90$ th percentile, Increased FBS: $\geq 100 \mathrm{mg} / \mathrm{dL}$; Increased Cholesterol: $\geq 200 \mathrm{mg} / \mathrm{dL}$. Abbreviations: OR, odds ratio; Cl, confidence interval; CE/PS, cognitive enhancers/psychostimulants; WC, waist circumferences; FBS, fasting blood sugar.

cardiovascular disease. ${ }^{57-61}$ It is also associated with MetS and type 2 diabetes. ${ }^{62}$ Previous local studies on adults and children demonstrated that low HDL was associated with increased triglycerides and central obesity among Palestinians. ${ }^{19,32-34,57,63}$ In agreement with these studies, our results showed that low HDL was the most prevalent metabolic abnormality among refugee schoolchildren (40\%). Moreover, central obesity and dyslipidemia were observed in tobacco smokers more than in non-smokers. Both cigarette and waterpipe smokers had decreased levels of HDL. At the same time, increased triglyceride levels were only observed in waterpipe smokers. Evidence from the literature suggests that both cigarettes and waterpipes in adults cause increased triglycerides. ${ }^{64}$ Waterpipe delivers 56-fold higher smoke volume compared to cigarettes. $^{65}$ Therefore, this considerably higher exposure could explain the effects of waterpipe on triglycerides compared to cigarettes. ${ }^{65}$ Association between waterpipe smoking and eating disorders was also observed among Palestinians in a previous study. ${ }^{66}$ This association could indicate that waterpipe smoking could be associated with unhealthy food behaviours for weight loss among Palestinians. Further investigation is recommended.

Based on univariate analysis results, both cigarette and waterpipe smokers were at a higher risk of having MetS than non-smokers. However, the adjusted binary logistic regression results revealed that no significant association with MetS for both. Smoking was associated with ED consumption, and the higher risk of MetS among smokers could be caused by their concurrent ED consumption. ${ }^{67}$
Further research is recommended to get more definitive answers about this association between smoking and MetS in children. Moreover, the gender-based ratio, male to female, in waterpipe smoking (4:1) was tighter than the cigarette smoking ratio (9:1). The tighter gap in gender ratio among waterpipe smokers is probably due to higher social acceptance of female waterpipe smoking than cigarette smoking. ${ }^{17}$ Since no studies were conducted previously to detect this population at risk, the narrow gender gap in this study emphasises the need for further studies to investigate the risk factors associated with increased risk of waterpipe smoking in females in the general Palestinian population.

Evidence from the literature suggests that coffee and tea are associated with decreased risk of MetS in adults. $^{68,69}$ However, our results suggest that black tea and coffee consumption were not significantly associated with triglyceride levels in refugee schoolchildren, in contrast to the results of a meta-analysis involving adults. ${ }^{70}$ Thus, the relationship between coffee consumption with MetS somehow remains vague. It needs more analysis and more research involving children to investigate further the association between these two substances and MetS and triglyceride levels. On the other hand, chocolate consumers have decreased levels of central obesity and increased levels of HDL than non-consumers. In agreement with a meta-analysis study involving adults, ${ }^{71}$ a significant reduction in MetS risk was associated with chocolate consumption among refugee schoolchildren. The protective effect probably results from flavonoids, which 
have a role in reducing oxidative stress, increasing the endothelial prostacyclin production, increasing insulin receptors sensitivity, altering lipid metabolism, and inhibiting angiotensin-converting enzyme. ${ }^{72}$ A previous local study demonstrated that chocolate consumption was associated with decreased risk of eating disorders among young Palestinians. ${ }^{66}$ It has been found that there is a relationship between guilt feeling when eating chocolate and developing abnormal eating behaviours; the high the guilt score, the more tendency to report symptoms such as binging and vomiting. ${ }^{73}$

This study has some limitations. Some limitations were caused by involving refugee schoolchildren from only the north of the West Bank. It also did not investigate CE/PS consumption quantitatively nor the quantity of consumed carbohydrates and caffeine. Moreover, no inferences could be made regarding causality as this is a cross-sectional study. Furthermore, this study was conducted during the COVID-19 pandemic. In the setting of COVID-19 quarantine, the possible effect of COVID-19 on CE/PS use among students is unknown. Moreover, physical activity, one of the critical factors which affect the prevalence of MetS and its components, was not evaluated in this research. Although this study has some limitations, it was the first study to suggest an association between ED consumption and MetS in refugee schoolchildren. Moreover, it was the first study to find an association between waterpipe smoking and high triglycerides levels in refugee schoolchildren.

\section{Conclusions}

The findings of this study present a serious threat to the current and future health of Palestinian refugee schoolchildren. The results showed an alarming prevalence of tobacco and caffeine use in refugee adolescents of both genders and those with metabolic syndrome, indicating that they are at higher risk of cardiovascular disease and coronary artery disease. Thus, their use justifies great attention. The high prevalence of ED consumption and waterpipe smoking among Palestinian refugee schoolchildren is problematic. Their use was associated with higher odds of metabolic syndrome and dyslipidemia among Palestinian refugee schoolchildren. This problem requires unique treatment and prevention strategies. Moreover, chocolate consumption was associated with a significantly decreased risk of MetS. Further investigation is required to address the direction of this relationship. It is known that levels of HDL are modifiable through behavioural factors, including smoking and diet. Smoking cessation is associated with an up to $10 \%$ increase in HDL level. ${ }^{74}$ Considering all these results, we recommend non-pharmacologic approaches that can effectively increase serum HDL levels in schoolchildren, including weight control, specific nutritional choices, and smoking cessation, to be adapted. ${ }^{57,75}$ Our findings suggest the need to integrate tobacco and caffeine products use prevention and treatment into preexisting health services offered to refugee adolescents in the West Bank by the United Nations Relief and Works Agency (UNRWA) to reduce future negative health consequences from their use. In previous national studies, the metabolic syndrome among tobacco and caffeine product users was an under-recognised and neglected health issue. We recommend further studies in other schoolchildren ages from different localities. Such studies are essential in drawing protective policies for vulnerable groups and studying the aetiology of metabolic syndrome.

\section{Abbreviations}

ANNU, An-Najah National University; ANOVA, analysis of variances; BMI, body mass index; BP, blood pressure; CDC, Centers for Disease Control and Prevention; CE, cognitive enhancers; CI, confidence interval; ED, energy drinks; FBS, fast blood sugar; HDL, high-density lipoprotein; IDF, International Diabetes Federation; LDL, lowdensity lipoprotein; MetS, metabolic syndrome; OR, odds ratio; PS, psychostimulants; UNRWA, United Nations Relief and Works Agency; WC, waist circumferences; WHO, World Health Organization.

\section{Data Sharing Statement}

Most data generated or analysed during this study are included in this manuscript. Other data that support the findings of this study and /or analysed during the current study are available from the corresponding author on reasonable request.

\section{Ethics Approval and Informed Consent}

We obtained informed consent from all subjects involved in the study and from their parents. Participants were informed that they could assent to or dissent from participation. Participants were assured that all data collected would only be kept confidential and accessible for the 
investigators and research purposes. The Ethics Committee of the Institutional Review Board "IRB" approval at An-Najah National University (ANNU) (IRB Archived number (16) Nov.2019) was obtained to confirm that the study matches the ethical research protocols. All procedures followed were following the ethical standards of the responsible committee on human experimentation (institutional and national) and with the Helsinki Declaration of 1975 , as revised in 2000 .

\section{Acknowledgments}

The authors would like to thank the respondents for their participation in this work. The authors are very thankful to all those who facilitated the conduction of this study in An-Najah National University Hospital (ANNU) and the Committee Services for Refugee Camps in Nablus and Tulkarm. The authors would like to thank Saba Damiri, Hiba Damiri, Mohammed Qino, and Yousef Qasim for their help in data collection.

\section{Author Contributions}

All authors contributed to data analysis, drafting, or revising the article, agreed to the journal to which the article will be submitted, gave final approval of the version to be published, and agreed to be accountable for all aspects of the work.

\section{Funding}

There is no funding to report.

\section{Disclosure}

The authors declare that they have no conflict of interest.

\section{References}

1. National Institute of Drug Abuse (NIDA). Principles of adolescent substance use disorder treatment; 2020. Available from: https:// www.drugabuse.gov/publications/principles-adolescent-substanceuse-disorder-treatment-research-based-guide. Accessed September 17, 2021.

2. Favrod-Coune T, Broers B. The health effect of psychostimulants: a literature review. Pharmaceuticals (Basel). 2010;3(7):2333-2361. doi:10.3390/ph3072333

3. Valentine G, Sofuoglu M. Cognitive effects of nicotine: recent progress. Curr Neuropharmacol. 2018;16(4):403-414. doi:10.2174/ 1570159X15666171103152136

4. Cappelletti S, Piacentino D, Sani G, Aromatario M. Caffeine: cognitive and physical performance enhancer or psychoactive drug? Curr Neuropharmacol. 2015;13(1):71-88. doi:10.2174/1570159X13666 141210215655

5. Damiri B, Ibrahim H, Khalaili M, Mohammad R, Imwas S. Tobacco and energy drinks, emerging health risk among Palestinian adolescent females, a cross-sectional study: call for action. J Concur Disord. 2020;1(1):7-18.
6. Damiri BR. The use of psychoactive substances in a conflict area in the west bank: drug use risk factors and practices in Palestinian refugee camps. Int J Ment Health Addict. 2020;18(6):1507-1520. doi:10.1007/s11469-019-00183-1

7. Massad SG, Shaheen M, Karam R, et al. Substance use among Palestinian youth in the West Bank, Palestine: a qualitative investigation. BMC Public Health. 2016;16(1):800. doi:10.1186/ s12889-016-3472-4

8. Frati P, Kyriakou C, Del Rio A, et al. Smart drugs and synthetic androgens for cognitive and physical enhancement: revolving doors of cosmetic neurology. Curr Neuropharmacol. 2015;13(1):5-11. doi:10.2174/1570159X13666141210221750

9. Lanni C, Lenzken SC, Pascale A, et al. Cognition enhancers between treating and doping the mind. Pharmacol Res. 2008;57(3):196-213. doi:10.1016/j.phrs.2008.02.004

10. Rusted JM, Sawyer R, Jones C, Trawley SL, Marchant NL. Positive effects of nicotine on cognition: the deployment of attention for prospective memory. Psychopharmacology. 2009;202(1-3):93-102. doi:10.1007/s00213-008-1320-7

11. Einöther SJ, Giesbrecht T. Caffeine as an attention enhancer: reviewing existing assumptions. Psychopharmacology. 2013;225 (2):251-274. doi:10.1007/s00213-012-2917-4

12. Nehlig A, Cunha RA, de Mendonça A. Is caffeine a cognitive enhancer? J Alzheimers Dis. 2010;20:S85-S94. doi:10.3233/JAD2010-091315

13. Rogers PJ, Heatherley SV, Mullings EL, Smith JE. Faster but not smarter: effects of caffeine and caffeine withdrawal on alertness and performance. Psychopharmacology. 2013;226(2):229-240. doi:10.10 07/s00213-012-2889-4

14. Musmar SG. Smoking habits and attitudes among university students in Palestine: a cross-sectional study. East Mediterr Health J. 2012;18 (5):454-460. doi:10.26719/2012.18.5.454

15. Zaher Nazzal MAA, Musmar S. Social norms and perception of waterpipe smoking among Palestinian university students. Palest Med Pharm J. 2020;5(1):25-34.

16. Damiri B, Sandouka HN, Janini EH, Yaish ON. Prevalence and associated factors of psychoactive substance use among university students in the West Bank, Palestine. Drug-Educ Prev Polic. 2020;27 (2):173-182. doi:10.1080/09687637.2019.1591341

17. Tucktuck M, Ghandour R, Abu-Rmeileh NME. Waterpipe and cigarette tobacco smoking among Palestinian university students: a cross-sectional study. BMC Public Health. 2017;18(1):1. doi:10.1186/s12889-017-4524-0

18. Al Sabbah H, Qamhia N, Younis M. Consumption patterns and side effects of energy drinks among university students in Palestine: cross-sectional study. MOJ Public Health. 2015;2(2):36-44. doi:10.15406/mojph.2015.02.00015

19. Damiri B, Abualsoud MS, Samara AM, Salameh SK. Metabolic syndrome among overweight and obese adults in Palestinian refugee camps. Diabetol Metab Syndr. 2018;10:34. doi:10.1186/s13098-018$0337-2$

20. Huang PL. A comprehensive definition for metabolic syndrome. Dis Model Mech. 2009;2(5-6):231-237. doi:10.1242/dmm.001180

21. Alberti KG, Zimmet P, Shaw J. Metabolic syndrome-a new worldwide definition. A Consensus Statement from the International Diabetes Federation. Diabetic Med. 2006;23(5):469-480. doi:10.1111/j.1464-5491.2006.01858.x

22. Grundy SM, Cleeman JI, Daniels SR, et al. Diagnosis and management of the metabolic syndrome: an American Heart Association/ National Heart, Lung, and Blood Institute Scientific Statement. Circulation. 2005;112(17):2735-2752. doi:10.1161/circulation aha.105.169404

23. DeBoer MD. Assessing and managing the metabolic syndrome in children and adolescents. Nutrients. 2019;11(8):1788. doi:10.3390/ nu11081788 
24. Fornari E, Maffeis C. Treatment of metabolic syndrome in children. Front Endocrinol (Lausanne). 2019;10:702. doi:10.3389/fendo.2 019.00702

25. Balhara YPS. Tobacco and metabolic syndrome. Indian J Endocrinol Metab. 2012;16(1):81-87. doi:10.4103/2230-8210.91197

26. Saha SP, Bhalla DK, Whayne TF, Gairola C. Cigarette smoke and adverse health effects: an overview of research trends and future needs. Int J Angiol. 2007;16(3):77-83. doi:10.1055/s-0031-1278254

27. Mansour B, Amarah W, Nasralla E, Elias N. Energy drinks in children and adolescents: demographic data and immediate effects. Eur J Pediatr. 2019;178(5):649-656. doi:10.1007/s00431-019-03342-7

28. Gallimberti L, Buja A, Chindamo S, et al. Energy drink consumption in children and early adolescents. Eur J Pediatr. 2013;172 (10):1335-1340. doi:10.1007/s00431-013-2036-1

29. Famurewa A, Folawiyo A, Epete M, Onuoha M, Igwe E. Consumption of caffeinated energy drink induces alterations in lipid profile and hepatic aminotransferases in experimental rats. $J$ Chem Pharm Res. 2015;7:363-369.

30. Wassef B, Kohansieh M, Makaryus AN. Effects of energy drinks on the cardiovascular system. World J Cardiol. 2017;9(11):796-806. doi:10.4330/wjc.v9.i11.796

31. Campbell B, Wilborn C, La Bounty P, et al. International Society of Sports Nutrition position stand: energy drinks. J Int Soc Sports Nutr. 2013;10(1):1. doi:10.1186/1550-2783-10-1

32. Damiri B, Badran L, Safadi D, et al. Metabolic syndrome and related risk factors among adults in the northern West Bank, a cross-sectional study. Trop Med Int Health. 2019. doi:10.1093/inthealth/ihz093

33. Damiri B, Alhala AA, Najjar L, Alqadome S. Metabolic syndrome and its risk factors among overweight and obese Palestinian schoolchildren using IDF and NCEP-ATP/III definitions. Ann Clin Lab Sci. 2018;6(3):8.

34. Damiri B, Aghbar A, Alkhdour S, Arafat Y. Characterization and prevalence of metabolic syndrome among overweight and obese young Palestinian students at An-Najah National University. Diabetes Metab Syndr. 2018;12(3):343-348. doi:10.1016/j. dsx.2017.12.021

35. Newcomb MD, Chou C-P, Builer PM, Huba GJ. Cognitive motivations for drug use among adolescents: longitudinal tests of gender differences and predictors of change in drug use. J Couns Psychol. 1988;35(4):426-438. doi:10.1037/0022-0167.35.4.426

36. Substance Abuse and Mental Health Services Administration. Key Substance Use and Mental Health Indicators in the United States: Results from the 2018 National Survey on Drug Use and Health (HHS Publication No. PEP19-5068, NSDUH Series H-54). Rockville, MD: Center for Behavioral Health Statistics and Quality, Substance Abuse and Mental Health Services Administration; 2019.

37. Anderson PJ, Critchley JA, Chan JC, et al. Factor analysis of the metabolic syndrome: obesity vs insulin resistance as the central abnormality. Int $J$ Obes (Lond). 2001;25(12):1782-1788. doi:10.1038/sj.ijo.0801837

38. Zimmet P, Alberti G, Kaufman F, et al. The metabolic syndrome in children and adolescents. Lancet. 2007;369(9579):2059-2061. doi:10.1016/s0140-6736(07)60958-1

39. Grundy SM, Stone NJ, Bailey AL, et al. 2018 guideline on the management of blood cholesterol: a report of the American College of Cardiology/American Heart Association Task Force on clinical practice guidelines. J Am Coll Cardiol. 2019;139(25):e1082-e1143. doi:10.1016/j.jacc.2018.11.002.

40. World Health Organization (WHO). Obesity and overweight; 2021. Available from: https://www.who.int/news-room/fact-sheets/detail/ obesity-and-overweight. Accessed September 17, 2021.

41. Centers for Disease Control and Prevention (CDC). Defining childhood weight status. BMI for children and teens; 2021; Available from: https://www.cdc.gov/obesity/childhood/defining. html. Accessed September 17, 2021.
42. Galimov A, Hanewinkel R, Hansen J, Unger JB, Sussman S, Morgenstern M. Energy drink consumption among German adolescents: prevalence, correlates, and predictors of initiation. Appetite. 2019;139:172-179. doi:10.1016/j.appet.2019.04.016

43. Wolk BJ, Ganetsky M, Babu KM. Toxicity of energy drinks. Curr Opin Pediatr. 2012;24(2):243-251. doi:10.1097/MOP.0b013e3 283506827

44. Nadeem IM, Shanmugaraj A, Sakha S, Horner NS, Ayeni OR, Khan M. Energy drinks and their adverse health effects: a systematic review and meta-analysis. Sports Health. 2021;13 (3):265-277. doi:10.1177/1941738120949181

45. Mattioli AV, Pennella S, Manenti A, Farinetti A. Energy drink overconsumption can trigger atrial fibrillation. $J$ Cardiovasc Med. 2016;17(12):902-904. doi:10.2459/jcm.0000000000000416

46. Kaşıkçığlu E. Sports, energy drinks, and sudden cardiac death: stimulant cardiac syndrome. Anatol J Cardiol. 2017;17(2):163-164. doi:10.14744/AnatolJCardiol.2017.7575

47. Iyadurai SJP, Chung SS. New-onset seizures in adults: possible association with consumption of popular energy drinks. Epilepsy Behav. 2007;10(3):504-508. doi:10.1016/j.yebeh.2007.01.009

48. Abdelaal M, le Roux CW, Docherty NG. Morbidity and mortality associated with obesity. Ann Transl Med. 2017;5(7):161. doi:10.21037/atm.2017.03.107

49. Al Sabbah H, Vereecken CA, Elgar FJ, et al. Body weight dissatisfaction and communication with parents among adolescents in 24 countries: international cross-sectional survey. BMC Public Health. 2009;9(1):52. doi:10.1186/1471-2458-9-52

50. Kostovski M, Simeonovski V, Mironska K, Tasic V, Gucev Z. Metabolic profiles in obese children and adolescents with insulin resistance. Open Access Maced J Med Sci. 2018;6(3):511-518. doi:10.3889/oamjms.2018.097

51. Higgins JP, Tuttle TD, Higgins CL. Energy beverages: content and safety. Mayo Clin Proc. 2010;85(11):1033-1041. doi:10.4065/ mcp.2010.0381

52. Peacock A, Martin FH, Carr A. Energy drink ingredients. Contribution of caffeine and taurine to performance outcomes. Appetite. 2013;64:1-4. doi:10.1016/j.appet.2012.12.021

53. Stanhope KL. Sugar consumption, metabolic disease and obesity: the state of the controversy. Crit Rev Clin Lab Sci. 2016;53(1):52-67. doi:10.3109/10408363.2015.1084990

54. Seifert SM, Schaechter JL, Hershorin ER, Lipshultz SE. Health effects of energy drinks on children, adolescents, and young adults. Pediatrics. 2011;127(3):511-528. doi:10.1542/peds.2009-3592

55. Eltahir HM, Alamri G, Alamri A, et al. The metabolic disorders associated with chronic consumption of soft and energy drinks in rats. Acta Biochimica Polonica. 2020;67(1):79-84. doi:10.18388/ abp.2020_2914

56. Trapp G, Hurworth M, Jacoby P, et al. Energy drink intake and metabolic syndrome: a prospective investigation in young adults. Nutr Metab Cardiovasc Dis. 2020;30(10):1679-1684. doi:10.1016/j. numecd.2020.06.012

57. Damiri B, Dudin B, Sharqiah Q, Khlaif H, Bsharat R, Amir M. Prevalence of low high-density lipoproteins (HDL) cholesterol and its related factors in adult Palestinians: a cross-sectional study. Palest Med Pharm J. 2021;6(2):00.

58. Rader DJ, Hovingh GK. HDL and cardiovascular disease. Lancet. 2014;384(9943):618-625. doi:10.1016/s0140-6736(14)61217-4

59. Yusuf S, Reddy S, Ôunpuu S, Anand S. Global burden of cardiovascular diseases: part I: general considerations, the epidemiologic transition, risk factors, and impact of urbanization. Circulation. 2001;104 (22):2746-2753. doi:10.1161/hc4601.099487

60. Hadaegh F, Harati H, Ghanbarian A, Azizi F. Prevalence of coronary heart disease among Tehran adults: Tehran Lipid and Glucose Study. East Mediterr Health J. 2009;15(1):57-66. doi:10.26719/ 2009.15.1.157 
61. Gordon T, Castelli WP, Hjortland MC, Kannel WB, Dawber TR. High density lipoprotein as a protective factor against coronary heart disease. Am J Med. 1977;62(5):707-714. doi:10.1016/00029343(77)90874-9

62. Marjani A. A review on HDL-cholesterol alterations in metabolic syndrome. $J$ Biol Sci. 2013;13(8):679-684. doi:10.3923/ jbs.2013.679.684

63. Massad SG, Khalili M, Karmally W, et al. Metabolic syndrome among refugee women from the West Bank, Palestine: a cross-sectional study. Nutrients. 2018;10(8):1118. doi:10.3390/ nu 10081118

64. Aslam HM, Saleem S, German S, Qureshi WA. Harmful effects of shisha: literature review. Int Arch Med. 2014;7:16. doi:10.1038/sj. ijo.0801837

65. Cobb CO, Shihadeh A, Weaver MF, Eissenberg T. Waterpipe tobacco smoking and cigarette smoking: a direct comparison of toxicant exposure and subjective effects. Nicotine Tob Res. 2011;13 (2):78-87. doi: $10.1093 /$ ntr/ntq212

66. Damiri B, Safarini O, Nazzal Z, et al. Eating disorders and the use of cognitive enhancers and psychostimulants among university students: a cross-sectional study. Who is at risk? Neuropsychiatr Dis Treat. 2021;17:1633-1645. doi:10.2147/NDT.S308598

67. Galimov A, Hanewinkel R, Hansen J, Unger JB, Sussman S, Morgenstern M. Association of energy drink consumption with substance-use initiation among adolescents: a 12-month longitudinal study. J Psychopharmacol. 2020;34(2):221-228. doi:10.1177/0269 881119895545
68. Yang CS, Zhang J, Zhang L, Huang J, Wang Y. Mechanisms of body weight reduction and metabolic syndrome alleviation by tea. Mol Nutr Food Res. 2016;60(1):160-174. doi:10.1002/mnfr.201500428

69. Baspinar B, Eskici G, Ozcelik AO. How coffee affects metabolic syndrome and its components. Food Funct. 2017;8(6):2089-2101. doi:10.1039/c7fo00388a

70. Cai L, Ma D, Zhang Y, Liu Z, Wang P. The effect of coffee consumption on serum lipids: a meta-analysis of randomized controlled trials. Eur J Clin Nutr. 2012;66(8):872-877. doi:10.1038/ ejcn.2012.68

71. Buitrago-Lopez A, Sanderson J, Johnson L, et al. Chocolate consumption and cardiometabolic disorders: systematic review and meta-analysis. BMJ. 2011;343:d4488. doi:10.1136/bmj.d4488

72. Adil M, Maazuddin OM, Amir S, Shoeb M, Adil U. Role of dark chocolate in minimising the risk of cardio-metabolic syndrome. Indo Am J Pharm Sci. 2013;2(3):6469-6476.

73. Benton D, Greenfield K, Morgan M. The development of the attitudes to chocolate questionnaire. Pers Individ Differ. 1998;24 (4):513-520. doi:10.1016/S0191-8869(97)00215-8

74. Barter PJ. The causes and consequences of low levels of high density lipoproteins in patients with diabetes. Diabetes Metab J. 2011;35 (2):101-106. doi:10.4093/dmj.2011.35.2.101

75. Ginsberg HN. Nonpharmacologic management of low levels of high-density lipoprotein cholesterol. Am J Cardiol. 2000;86 (12):411-451. doi:10.1016/s0002-9149(00)01469-7

Diabetes, Metabolic Syndrome and Obesity: Targets and Therapy

Dovepress

\section{Publish your work in this journal}

Diabetes, Metabolic Syndrome and Obesity: Targets and Therapy is an international, peer-reviewed open-access journal committed to the rapid publication of the latest laboratory and clinical findings in the fields of diabetes, metabolic syndrome and obesity research. Original research, review, case reports, hypothesis formation, expert opinion and commentaries are all considered for publication. The manuscript management system is completely online and includes a very quick and fair peer-review system, which is all easy to use. Visit http://www.dovepress.com/testimonials.php to read real quotes from published authors.

Submit your manuscript here: https://www.dovepress.com/diabetes-metabolic-syndrome-and-obesity-targets-and-therapy-journal 